of deficit reduction, substantial cuts seem inevitable.

The universities also suffer from some serious disabilities in terms of their lobbying efforts. In an egalitarian society, some of the elitist characteristics of the more traditional Australian universities mean that they often find difficulty in attracting strong public support for their causes.

Minister Vanstone has put the peak organization representing heads of universities, the Australian Vice-Chancellors' Committee (AVCC), in a difficult position in that she has twice responded to AVCC lobbying efforts by inviting the AVCC to work with her officials in advising where the cuts should be made. So far the AVCC has refused, since it has taken the public stance that there should be no cuts at all, although another reason is that representing such a diverse set of universities the AVCC would find it difficult to provide advice.

A number of individual vice-chancellors (i.e., executive heads or presidents, in American terminology), however, have not been slow to make suggestions, at least with regard to where not to make cuts and on revenue generation possibilties. Some parties representing the big eight universities, have been emphasizing the importance of maintaining funding to the strong research universities, while nonmetropolitan regional universities have been pushing for special protection. Others have effectively suggested strategies for differential treatment by advocating that the cuts should fall more heavily on the universities that have greater reserves and endowments. Others still have suggested that two or three regional universities will have to be closed.

But apart from this sectional discussion, some useful suggestions have been made. These include revenue generation suggestions as variations in the current HECS (i.e., Higher Education Contribution Scheme-effectively a graduate tax) levy and the rate of HECS liability repayment by graduates, charging of tuition fees for nonresearch higher degree enrollments, and taxation benefits for private investment in higher education. A few have also suggested an end to the embargo on the charging of tuitition fees for undergraduates.

If the cuts go ahead the end result will certainly be a trimmer and probably quite different higher education system.

\section{Democracy and Higher Education in Paraguay}

\section{Vicente Sarubbi Zaldivar}

Vicente Sarubbi is a founding member of the Advisory Council of Education Reform in Paraguay. He has taught in the Catholic University of Asuncion and has been director of a major newspaper. He is currently the director of a project to improve primary education in Paraguay and academic vice-president of the Escuela de Altos Estudios de Administración y Negocios.

ince 1989 Paraguay has been trying to establish a democracy. Extending this process will require a true educational revolution. To promote an open society, which is the foundation of democratic government, it is important to invest in basic education, science and technology in a serious and selective way. Paraguay would then be able to integrate itself with countries in the region and in the rest of the world, thus contributing to the consolidation of a nation based on law. This article highlights the most important aspects of the necessary fundamental changes within higher education in Paraguay.

It is appropriate to ponder the role of higher education at a time of crisis that calls for a deep reform of its orientation and of its institutions. This crisis is characterized by insufficient coverage, low levels of performance, insufficient and dated ideas about the functions of the university, highly bureaucratized administration, inadequate moral and intellectual development of students, lack of professional teaching standards, and irrelevance of the curriculum for the purposes of production, government, and life in general.

\section{Analysis and Prospects}

The points of analysis in this article are related, on the one hand, to the need for up-to-date scientific and technological knowledge-so essential in a modern economy-in a context of regional integration and globalization of world markets, and on the other, to the need to correct the consequences of a history of authoritarianism and corruption in the country. The professional training received is recognized as being of doubtful quality, lacking in the basic scientific knowledge and technological know-how that our times require. This means Paraguayan graduates will be at a comparative disadvantage vis à vis those of the other countries of the Southern Regional Common Market (MERCOSUR). This same deficiency in professional training limits the ability of the country-just emerging from a long period of authoritarianism and dictatorship-to produce political leaders, public and private administrators, jour- 
nalists, intellectuals, artists, a military, and teachers who are ethically and critically well trained, with democratic attitudes and convictions.

Access to higher education is extremely limited—even considering the inadequate availability of secondary education, there are more people who want to pursue higher education than spaces available to them. Trends indicate this gap between supply and demand will worsen in the near future. There is also insufficient research being conducted at the universities. Current levels of funding and the structures of training, recruitment, and remuneration of university researchers or teacher-researchers do not allow a change in current conditions in this respect. In a global economy-in which, increasingly, the acquisition, creation and application of scientific and technological knowledge for the production of goods and services is a strategic resource-this deficiency makes it impossible for Paraguay to participate in the international community and in the global markets-not even within the boundaries of MERCOSUR. The almost complete lack of a scientific culture in our institutions of higher education hinders not just developments in the basic or applied sciences, but even the intelligent acquisition of such knowledge and skills.

Public funding for higher education — absurdly insufficient relative to what other countries in the region invest in higher education-must compete with the needs of preschool, basic, and secondary education. The National University of Asuncion dominates the public sector. As their main source of financing tuition, private institutions have fees, and a limited number of contracts for services provided to the public or private sectors.

The Challenges and Mission of Higher Education in Paraguay In a pluralistic society such as those in Europe or in North America, education is vitally important for promoting freedom of opportunity. In such societies success is not a function of family social background, but rather of education and real potential. In these societies, the emergence of education as an engine of equal opportunity coincided with the transition from a stratified society to a pluralistic society —one that is respectful of human dignity and, ultimately, of ecological needs.

The fall of dictatorship in 1989 had the immediate effect of unfreezing the social and political situation, in addition to ending the country's isolation from the rest of the world. But while change in individuals and social systems is possible, it takes time. The case is particularly difficult when, as is the case with Paraguay, what is desired is structural change. Democratization has advanced in Paraguay to the extent that all public and private liberties have been recognized. The freedom to elect and be elected, the possibility of change in government and complete freedom of speech are necessary components of democracy in Paraguay, but they are not sufficient. It is necessary to develop a democratic culture, based on mutual recognition, acceptance of differences, respect for others, and a commitment to true equality based on social justice. The main objective of higher education in Paraguay should be to contribute to the development of this democratic culture.

Another important mission of the university is to launch an offensive against authoritarianism and corruption. Authoritarian rule has a long tradition in Paraguay. Along with selective repression and corruption, structural forms of control adopted by the government were not so much for enriching those close to power, as for staying in power. Under the current democratic reforms, Paraguay is exposed to the many external forces of the modern world. It will be essential to facilitate, through the education system, a change in the attitudes, mindset, and behaviors of the actors within the education community, beginning with the teachers, administrators, parents, and leaders in society.

\section{Conclusion.}

The Paraguayan system of higher education should aim toward academic excellence of research, teaching, and service-in keeping with international standards-while at the same time expanding coverage. Higher education should be in a position to respond to the priorities of education reform and the challenges of democratization and sustainable and ecological development. Higher education should become a strategic player in Paraguayan economic development. Knowledge generated in the universities should help us understand the growing complexities of the economy and of world and regional politics.

In summary, the evolution of such a system of higher education means massive change. Instead of looking like an ivory tower-protecting the knowledge and the privilege of conferring prestige and social status-the university should be an opportunity offered to most of the citizens, and to the community at large, to support the individual improvement and the quality of life of the whole population. This requires a fundamental change in perspective: to stop seeing the world as a place of scarcity, or of distant possibilities, and instead see it as abundant and within reach of all. Accepting this change of perspective will mean, for Paraguay, a move toward economic growth with equity. 